Joyful Learning Journal

\title{
KEEFEKTIFAN MODEL TIME TOKEN BERBANTUAN FLASHCARD TERHADAP HASIL BELAJAR PPKn KELAS II
}

\author{
Duta Prima Manunggal ${ }^{\bowtie}$, Moh. Fathurrahman
}

Jurusan Pendidikan Guru Sekolah Dasar, Fakultas Ilmu Pendidikan, Universitas Negeri Semarang, Indonesia

\begin{tabular}{l}
\hline Info Artikel \\
\hline Sejarah Artikel: \\
Diterima Oktober 2020 \\
Disetujui Novwmber 2020 \\
Dipublikasikan Desember \\
2020 \\
\hline Keywords: \\
civic education; effectiveness; \\
flashcard; learning outcome; \\
time token \\
\end{tabular}

\begin{abstract}
Abstrak
Penelitian ini bertujuan untuk mendeskripsikan hasil belajar dalam pembelajaran PPKn dengan menggunakan model time token berbantuan media flashcard dan model direct instruction berbantuan media gambar di kelas II SD Gugus Piere Tendean dan untuk menguji keefektifan model time token berbantuan media flashcard daripada model direct instruction berbantuan media gambar terhadap hasil belajar PPKn materi keberagaman karakteristik individu di sekolah kelas II SD Gugus Piere Tendean Kaliwungu Kendal. Penelitian ini menggunakan metode kuantitatif jenis penelitian yang digunakan ialah eksperimen dan desain nonequivalent control group design. Teknik sampel yang digunakan adalah cluster random sampling, dengan sampel sebanyak 51 siswa. Pengumpulan data menggunakan tes, observasi dan dokumentasi. Hasil uji hipotesis menunjukkan bahwa nilai $t_{\text {hitung }}=3,132$, dan $t_{\text {tabel }}=$ 2,010 , karena $t_{\text {hitung }}>\mathrm{t}_{\text {tabel }}(3,132>2,010)$ yang berarti model time token berbantuan media flashcard efektif digunakan pada pembelajaran PPKn kelas II SD. Hasil uji n-gain kelas eksperimen lebih tinggi yaitu nilai n-gain kelas kontrol adalah 0,293970401 tergolong kriteria rendah dan nilai n-gain kelas eksperimen adalah 0,39691064 tergolong kriteria sedang. Simpulan penelitian ini yaitu model pembelajaran time token berbantuan media flashcard efektif digunakan pada pembelajaran PPKn siswa kelas II SD Gugus Piere Tendean Kaliwungu Kendal.
\end{abstract}

This study aims to describe the learning outcomes in learning civic education by using a time token model assisted by flashcard media and direct instruction model assisted by image media in $2^{\text {nd }}$ grade SD Piere Tendean Cluster and to test the effectiveness of the time token model assisted by a flashcard media a picture of the learning outcomes of the civic education material on the diversity of individual characteristics in $2^{\text {nd }}$ grade Primary Schools in the Piere Tendean Kaliwungu Kendal cluster. This research uses quantitative methods, the type of research used is experimental and nonequivalent control group design. The sampling technique used was cluster random sampling, with a sample of 51 students. Data collection uses tests, observations and documentation. Hypothesis test results show that the value of $t$-count $=3.132$, and $t$-table $=2.010$, because $t$-count $>t$-table $(3.132>2.010)$, which means that the time token model assisted by flashcard media is effectively used in learning the civic education $2^{\text {nd }}$ grade SD. The n-gain test results of the experimental class were higher namely, the value of the n-gain of the control class was 0.293970401 , classified as a low criterion and the n-gain value of the experimental class was 0.39691064 , classified as a medium criterion. This research concludes that the time token learning model assisted by flashcard media is effectively used in learning civic education for $2^{\text {nd }}$ grade students of the Primary School in the Kaliwungu Kendal Group.

(C) 2020 Universitas Negeri Semarang

$\begin{array}{lr}\text { Alamat korespondensi: } & \text { ISSN 2252-6366 } \\ \text { Banjarmulya RT 02 RW 11 Pemalang Pemalang } & \\ \text { E-mail: duthaxp@gmail.com } & \end{array}$




\section{PENDAHULUAN}

Pendidikan Kewarganegaraan (PPKn) merupakan salah satu mata pelajaran yang ada di Sekolah Dasar. Sesuai dengan Permendikbud Nomor 21 Tahun 2016 tentang Standar Isi Pendidikan Dasar Kurikulum 2013 menetapkan bahwa PPKn memiliki beberapa tingkat kompetensi dan dipusatkan pada pembentukan karakter individu yang memahami dan mampu menjalankan hak dan kewajibannya menjadi warga negara Indonesia yang cerdas, terampil, serta berkarakter.

Setiap usaha pendidikan memiliki tujuan tertentu yang ingin dicapai. Hardini (2015:121) mengemukakan bahwa tujuan PPKn yaitu berpikir secara kritis, logis, dan inovatif dalam menghadapi isu kewarganegaraan serta berperan secara aktif dan penuh tanggung jawab, serta bertindak secara cermat dalam kehidupan bermasyarakat, berbangsa, dan bernegara; Menurut Susanto (2013:227) mengemukakan bahwa pembelajaran PPKn di SD dimaksudkan sebagai suatu proses belajar mengajar untuk membantu siswa agar dapat belajar dengan baik dan membentuk manusia Indonesia seutuhnya dalam pembentukan karakter bangsa yang berlandaskan Pancasila, UUD, dan norma-norma yang berlaku di masyarakat.

Tujuan PPKn tersebut sudah sesuai dengan perkembangan ilmu pengetahuan secara global. Namun pada faktanya, masih terdapat beberapa permasalahan pada pelaksanaan pembelajaran PPKn di Indonesia. Pembelajaran PPKn dari jenjang pendidikan dasar hingga menengah masih belum mencapai tujuan. Berdasarkan hasil temuan Widiatmaka (2016:191) mengungkapkan bahwa permasalahan yang seringkali terjadi dalam pembelajaran PPKn yaitu (1) selalu menekankan aspek kognitif sehingga karakter peserta didik masih kurang diperhatikan; (2) pemerataan guru atau pendidik di setiap daerah, karena di daerah pinggiran dan daerah lain masih kekurangan guru; (3) kompetensi guru di Indonesia belum mampu menguasai 4 kompetensi (pedagogik, profesional, sosial dan kepribadian) secara menyeluruh; dan (4) metode pembelajaran yang digunakan oleh guru di dalam proses pembelajaran yang monoton (cenderung menggunakan metode ceramah.

Berdasarkan data melalui kegiatan observasi, wawancara dan data dokumen berupa hasil belajar siswa kelas II SD Gugus Piere Tendean Kaliwungu Kendal ditemukan beberapa masalah dalam pembelajaran. Masalah yang ditemui peneliti meliputi rendahnya minat belajar siswa disebabkan oleh guru cenderung masih mendominasi pembelajaran, diskusi kelompok sudah dilakukan, namun dalam pelaksanaannya belum optimal. Dalam penerapan model pembelajaran, guru cenderung menggunakan model direct instruction, hal ini dilakukan agar lebih mudah dalam proses pembelajaran yaitu dengan pemebelajaran langsung. Media pembelajaran yang digunakan yaitu media teks dan media gambar. Gambar yang dicetak berukuran kecil dan tidak terlihat sampai belakang, terkadang siswa yang duduk dibelakang maju kedepan kelas untuk melihat gambar dan hal ini membuat suasana kelas menjadi tidak kondusif dan ramai, sehingga antusias siswa dalam mengikuti pembelajaran kurang dan berdampak pada hasil belajar siswa. Permasalahan tersebut didukung dengan perolehan hasil belajar Penilaian Akhir Semester ganjil siswa kelas II tahun pelajaran 2018/2019 pada muatan pelajaran PPKn. Dari data tersebut diketahui bahwa hasil belajar PPKn di SD Gugus Piere Tendean masih rendah dibuktikan dari 120 jumlah seluruh siswa kelas II ada 57 siswa (48\%) yang mendapat nilai dibawah KKM dan sisanya yaitu 63 siswa (52\%) yang mendapat nilai diatas KKM.

Berdasarkan permasalahan tentang pembelajaran PPKm tersebut peneliti ingin menguji keefektifan model dan media pembelajaran yaitu model time token berbantuan media flashcard terhadap dengan model pembelajaran direct instruction berbantuan media gambar. Model time token berbantuan media flashcard diharapkan dapat meningkatkan keefektifan siswa memperoleh hasil belajar yang maksimal serta dapat meningkatkan rata-rata hasil belajar selama proses pembelajaran berlangsung.

Menurut Shoimin (2014:216) model time token (kupon berwaktu) merupakan model pembelajaran yang melatih dan mengembangkan keterampilan sosial agar siswa tidak mendominasi pembicaraan atau diam sama sekali, Ariffudin (2018:23) menambahkan bahwa model pembelajaran kooperatif itu merujuk pada teori konstruktivisme bilamana di dalam pembelajaran melibatkan siswa untuk bekerjasama dalam kelompok dan memiliki sistem pembelajaran terintegrasi. Sedangkan menurut Aqib (2013: 33) model time token menerapkan model pembelajaran kooperatif yang terstruktuk dapat digunakan untuk mengajarkan keterampilan sosial peserta didik.

Model time token ini akan lebih efektif apabila berbantuan media pembelajaran yang menarik pula. Hal ini sejalan dengan pendapat Fakhruddin (2017:109) bahwa untuk menciptakan pembelajaran yang berkualitas dan bermakna dapat dilakukan dengan adanya penggunaan media. Menurut Ahmadi (2017:129) fungsi media pembelajaran salah 
satunya sebagai sumber belajar. Widihastrini (2016:8) menambahkan bahwa media pembelajaran dapat melancarakan proses interaksi guru dan siswa. Media pembelajaran yang dapat mendukung model time token salah satunya adalah media flashcard. Menurut Arsyad (2014:119) flashcard merupakan kartu kecil yang berisi gambar biasanya berukuran $8 \times 12 \mathrm{~cm}$ dan dibuat semenarik mungkin yang mana dapat menuntun siswa kepada sesuatu yang berhubungan dengan gambar tersebut.

Penelitian yang mendukung pemecahan masalah dalam peneltian ini adalah penelitian yang dilakukan Widyastuti (2015) dengan judul Efektifitas Model Pembelajaran Time Token Arends Terhadap Keterampilan Berbicara Bahasa Indonesia Siswa Kelas V SD Bakalan Sewon Bantul Tahun Ajaran 2015/2016 yang mengemukakan bahwa model time token lebih efektif untuk meningkatkan hasil belajar dan keterampilan berbicara Bahasa indonesia siswa kelas V SD Bakalan Sewon Bantul.

Penelitian yang dilakukan oleh Hussaini (2016:22) dengan judul Improving Nigerian and Malaysian Primary School Students Vocabulary Skills Using Flash Cards menunjukkan bahwa siswa yang menggunakan flashcards dalam kelompok eksperimen miliki skor rata-rata yang lebih baik dalam post-test. Penggunaan kartu flash merupakan salah satu cara yang efektif untuk meningkatkan penguasaan kosakata siswa dalam belajar Inggris.

Rumusan masalah dalam penelitian ini yaitu bagaimanakah hasil belajar PPKn menggunakan model Time Token berbantuan media flashcard dengan model Direct Instruction (Pembelajaran Langsung) berbantuan media gambar untuk siswa kelas II di SD Gugus Piere Tendean Kaliwungu Kendal dan apakah pembelajaran PPKn menggunakan model Time Token berbantuan media flashcard lebih efektif digunakan daripada menggunakan model Direct Instruction (Pembelajaran Langsung) berbantuan media gambar untuk siswa kelas II di SD Gugus Piere Tendean Kaliwungu Kendal?

Berdasarkan rumusan masalah tersebut, tujuan penelitian ini yaitu mendeskripsikan hasil belajar PPKn menggunakan model Time Token berbantuan media flashcard dengan model Direct Instruction (Pembelajaran Langsung) berbantuan media gambar untuk siswa kelas II di SD Gugus Piere Tendean Kaliwungu Kendal dan untuk menguji keefektifan model pembelajaran Time Token berbantuan media flashcard lebih efektif terhadap dalam pembelajaran PPKn untuk siswa kelas II di SD N Gugus Piere Tendean Kaliwungu Kendal.

\section{METODE PENELITIAN}

Penelitian ini menggunakan metode kuantitatif dengan jenis penelitian eksperimen dan menggunakan desain nonequivalent control group design. Populasi dalam penelitian ini yaitu siswa kelas II SD Gugus Piere Tendean Kaliwungu Kendal yang berjumlah 120 siswa. Teknik pengambilan sampel yang digunakan yaitu cluster random sampling. Sampel dalam penelitian ini adalah siswa kelas II SDN Nolokerto 02 sebagai kelas eksperimen dengan jumlah 26 siswa dan SDN Sumberejo 03 sebagai kelas kontrol dengan jumlah 25 siswa. Variabel bebas dalam penelitian ini yaitu model time token berbantuan media flashcard dan variabel terikat yaitu hasil belajar PPKn.

Teknik pengumpulan data dalam penelitian ini yaitu tes, observasi, dan dokumentasi. Analisis perangkat tes berupa uji validitas, reliabilitas, taraf kesukaran soal dan daya beda soal sebelum instrumen digunakan dalam pengambilan data. Teknik analisis terdiri atas analisis data awal dan analisis data akhir. Analisis data awal yaitu uji normalitas dan uji homogenitas, sedangkan analisis data akhir yaitu uji normalitas, uji homogenitas, uji hipotesis dan uji n-gain.

Penghitungan uji normalitas, uji homogenitas, uji hipotesis menggunakan bantuan SPSS23. Uji hipotesis menggunakan uji-t berfungsi untuk mengetahui keefektifan model time token berbantuan flashcard pada kelas ekperimen terhadap hasil belajar PPKn. Perhitungan uji-t menggunakan independent sample t-test dengan bantuan SPSS23. Kriteria pengujian menurut Priyatno (2017:201) yaitu apabila $t_{\text {hitung }}>t_{\text {tabel }}$ dengan nilai signifikasi $>$ 0,05, maka $\mathrm{H}_{0}$ ditolak. Sedangkan uji n-gain digunakan untuk menguji adanya perbedaan peningkatan rata-rata antara nilai pretest dan posttest pada kelas kontrol dan kelas eksperimen

\section{HASIL DAN PEMBAHASAN}

Hasil dari penlitian menunjukkan modus nilai pretest kelas kontrol yaitu 57 sedangkan modus nilai pretest kelas eksperimen yaitu 67 . Modus pada posttest yang ada di kelas kontrol yaitu 70 dan modus nilai posttest yang ada di kelas eksperimen yaitu 83. Standar devisiasi pada pretest kelas kontrol yaitu 11,510 sedangkan standar devisiasi nilai pretest kelas eksperimen yaitu 9,795. Standar devisiasi pada posttest yang ada di kelas kontrol yaitu 9,381 dan Standar deviasiasi posttest yang ada di kelas eksperimen yaitu 11,658. Pada kelas kontrol memiliki rata-rata hasil pretest sebesar 58,40565 dan kelas eksperimen sebesar 66,41077. Ratarata hasil posttest kelas kontrol sebesar 70,4408 sedangkan pada kelas eksperimen sebesar 
79,74269. Terdapat selisih hasil rata-rata nilai posttest siswa di kelas ekperimen dan kelas kontrol antara pembelajaran yang menggunakan model time token berbantuan media flashcard dan pembelajaran yang menggunakan model direct instruction berbantuan media gambar.

Sebelum melakukan uji hipotesis, dilakukan uji normalitas dan homogenitas data posttest. Perhitungan uji normalitas data menggunakan SPSS23 uji Kolmogorov Smirnov. Uji normalitas data dapat terpenuhi apabila nilai Sig $>\alpha=0,05$, diperoleh hasil bahwa data posttest kelas kontrol berdistribusi normal $(0,174$ $>0,05)$ dan kelas eksperimen berdistribusi normal $(0,066>0,05)$. Uji homogenitas data menggunakan SPSS23 dengan uji One-Way $A N O V A$. Kriteria pengujian apabila nilai Sig $>$ $\alpha=0,05$ maka varian homogen. Hasil perhitungan uji homogenitas diperoleh bahwa $0,446>0,05$, sehingga dapat disimpulkan bahwa data posttest kelas eksperimen dan kelas kontrol tersebut homogen atau memiliki variasi/keragaman nilai yang sama.

Untuk mengetahui perbedaan rata-rata dilakukan pengujian hipotesis akhir menggunakan bantuan SPSS23 dengan uji independent sample ttest. Hasil perhitungan menunjukkan bahwa harga $t_{\text {hitung }}$ sebesar 3,132 lebih besar terhadap dengan harga $t_{\text {tabel }} 2,010$ $(3,132>2,005)$ artinya $\mathrm{H}_{0}$ ditolak dan $\mathrm{Ha}$ diterima. Kesimpulannya bahwa hipotesis yang menyimpulkan penerapan model pembelajaran time token berbantuan media flashcard efektif bila terhadap dengan model pembelajaran direct instruction berbantuan media gambar. Hasil uji hipotesis tersebut dapat dilihat dalam tabel berikut:

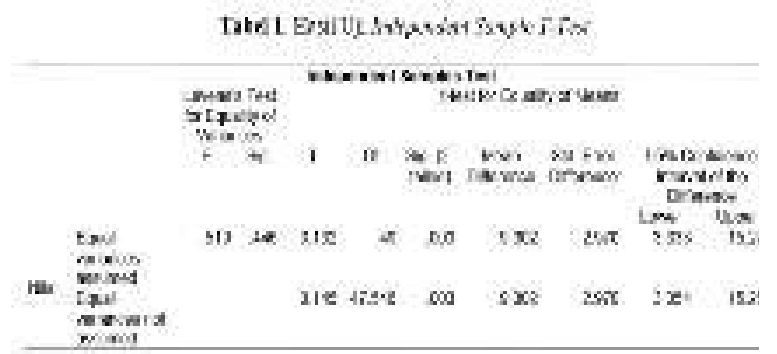

Hasil penelitian ini sejalan dengan penelitian yang telah dilakukan oleh Ni'mah (2018:3.447) menunjukkan nilai rata-rata skor hasil pretest pada kelas eksperimen siswa 64,62 meningkat menjadi 81,73 pada hasil posttest. Sedangkan rerata akhir keterampilan' sosial siswa kelas kontrol 8,86 dan eksperimen 9,84. Hasil uji ttest hasil belajar 0,043 dan t-test keterampilan sosial 0,012. Dengan demikian terdapat perbedaan peningkatan hasil belajar matematika siswa yang signifikan antara kelas eksperimen dan kelas kontrol.

Penelitian yang dilakukan oleh Setiawati (2015:1) yang menyatakan bahwa terdapat perbedaan rata-rata hasil belajar siswa dengan penggunaan media flashcard, dibuktikan dengan harga $t_{\text {hitung }}$ sebesar 26,58 dimana harga $t_{\text {tabel }}$ dengan taraf signifikansi 5\% diperoleh sebesar 2,201 sehingga bisa dinyatakan harga $t$ yang diperoleh signifikan. Hal ini berarti terdapat pengaruh pembelajaran dengan media gambar flashcard terhadap minat belajar IPA.

Keefektifan model pembelajaran time token ditunjukkan adanya peningkatan hasil belajar kognitif pada siswa kelas eksperimen setelah mendapatkan perlakuan. Dibuktikan dengan nilai pretest dan posttest dari kelas eksperimen dan kelas kontrol menggunakan uji gain untuk mengetahui peningkatan rata-rata dari masing-masing kelas. Berdasarkan nilai $n$ gain, kelas eksperimen mendapatkan n-gain sebesar yaitu 0,39691064 termasuk kategori sedang, sedangkan nilai n-gain kelas kontrol sebesar yaitu 0,293970401 termasuk kategori rendah. Berdasarkan tingkat ketuntasan, pada kelas eksperimen sebanyak 20 siswa (76,92\%) mendapatkan nilai posttest yang memenuhi Kriteria Ketutasan Minimal (KKM), sedangkan pada kelas kontrol, yang mendapat nilai memenuhi KKM sebanyak 10 siswa (40\%). Hasil uji n-gain tersebut dapat dilihat pada diagram berikut:

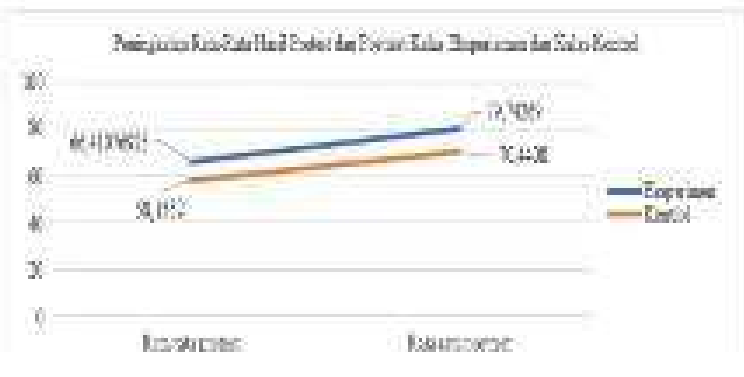

Gambar 1. Diagram Peningkatan Ratarata Hasil Belajar PPKn Kelas Kontrol dan Eksperimen

Hasil Penelitian ini relevan dengan penelitian yang dilakukan oleh Artawan, dkk (2019:111) menjelaskan bahwa terdapat pengaruh yang signifikan proses pembelajaran menggunakan model time token terhadap hasil belajar bahasa Indonesia siswa. Hal ini dibuktikan dengan uji-t, diperoleh nilai thitung $=2,42$ lebih besar dari ttabel $=2,006$ dengan taraf signifikasi 5\%. Di samping itu, didapatkan pula bahwa mean kelompok ekperimen adalah 29 dan mean kelompok kontrol adalah 26,29. Dapat disimpulkan bahwa penerapan model time token dapat meningkatkan hasil belajar siswa.

Penelitian lain yang mendukung penelitian ini yaitu penelitian oleh Safitri, dkk. (2018:1) yang menunjukkan bahwa penggunaan media flashcard dapat meningkatkan hasil belajar pada pembelajaran tematik berbasis 
permainan tradisional subbtema Lingkungan Tempat Tinggalku yang berisikan muatan PPKn didalamnya, hal ini dibuktikan dari hasil validasi dari dua validator ahli aspek media dan materi menunjukkan bahwa media sangat layak digunakan dalam pembelajaran, hasil respon siswa skala kecil dan luas menunjukkan bahwa media sangat layak dengan persentase $100 \%$ dan hasil belajar sebelum dan setelah diberi perlakuan menunjukkan perbedaan yang signifikan, uji hipotesis pembelajaran 2 diperoleh thitung $=8,376>$ tabel $=2,093$, dalam pembelajaran 5 diperoleh thitung $=7,264$ $>$ ttabel $=2,093$. Hal ini menunjukkan bahwa media flashcard dapat meningkatkan hasil belajar siswa. Adapun penelitian yang dilakukan oleh Awang (2016:433) dengan judul An Action Research on the Effectiveness Uses of Flash Card in Promoting Hijaiyah Literacy among Primary School Pupils. Hasil penelitian menunjukkan bahwa penggunaan flash card benar-benar membantu siswa untuk menjadi lebih familiar dan mudah mengingat huruf hijaiyah.

\section{SIMPULAN}

Berdasarkan hasil penelitian dan pembahasan dapat disimpulkan bahwa rata-rata nilai pretest kelas kontrol yaitu 58,1332, sedangkan rata-rata nilai pretest kelas eksperimen yaitu 66,41077. Pada rata-rata posttest yang ada di kelas kontrol yaitu 70,4408 dan rata-rata nilai posttest yang ada di kelas eksperimen yaitu 79,74269, sedangkan hasil perhitungan menggunakan Independent Sample T-Test diketahui nilai $t_{\text {hitung }}$ adalah 3,132, sedangkan nilai $t_{\text {tabel }}$ yaitu 2,010 . Karena $t_{\text {hitung }}=$ $3,132>t_{\text {tabel }}=2,010$ maka $\mathrm{H}_{0}$ ditolak. Dengan demikian dapat disimpulkan bahwa $\mathrm{H}_{0}$ ditolak dan Ha diterima, sehingga model pembelajaran time token berbantuan flashcard lebih efektif terhadap model direct instruction berbantuan gambar terhadap hasil belajar PPKn siswa kelas II SD Gugus Piere Tendean Kaliwungu Kendal. Sedangkan pengamatan yang dilakukan di kelas kontrol dan kelas eksperimen muatan pelajaran PPKn materi keberagaman karakteristik individu di sekolah menunjukkan bahwa adanya selisih rata-rata hasil belajar. Pada kelas kontrol diperoleh n-gain sebesar 0,293970401 dengan kriteria rendah, sedangkan pada kelas eksperimen diperoleh ngain sebesar 0,39691064 dengan kriteria sedang.

\section{UCAPAN TERIMA KASIH}

Penulis mengucapkan terima kasih kepada dosen pembimbing Moh. Fathurrahman, S.Pd.,M.Sn.dan mitra bestari Dra. Florentina Widihastrini, M.Pd. serta
Susilo Tri Widodo, S.Pd, M.H. yang telah memberikan bimbingan, masukan, dan arahan dalam menyusun manuskrip ini.

\section{DAFTAR PUSTAKA}

Ahmadi, F., Sutaryono, Witanto Y., \& Ratnaningrum, I. (2017). Pengembangan Media Edukasi "Multimedia Indonesia Culture" (MIC) sebagai Penguatan Pendidikan Karakter Siswa Sekolah Dasar. Jurnal Penelitian Pendidikan, 34(2):127-136.

Ariffudin, dkk. (2018). A Learning Model of Environmental Education Integrated With Pair Check and Guided Inquiry Method. IOSR Journal of Research \& Method in Education, 8(4): 22-28.

Aqib, Zainal. 2015. Model-Model, Media, dan Strategi Pembelajaran Kontekstual (Inovatif). Bandung: Yrama Widya.

Arsyad, Azhar. 2014. Media Pembelajaran. Jakarta: PT. Rajagrafindo Persada.

Artawan, I. Putu, Ni Wayan Arini, and Desak Putu Parmiti. "Pengaruh Pendekatan Saintifik Proses Mengomunikasikan Dalam Model Time Token Terhadap Hasil Belajar Bahasa Indonesia." Journal of Education Technology 3.2 (2019): 111118 .

Awang, Muhamad Zahiri., dkk. (2016). An Action Research on the Effectiveness Uses of Flash Card in Promoting Hijaiyah Literacy among Primary School Pupils. Mediterranean Journal of Social Sciences. 7(2): 433-438.

Fakhruddin, Ahmadi, F., Sumilah, \& Ansori, I. (2017). IBM Guru Sekolah Dasar Melalui Upaya Peningkatan Kualitas Guru dengan Pelatihan Pengembangan Media Pembelajaran pada Implementasi Kurikulum 2013. ABDIMAS, 21(2): 103110.

Hardini, T. (2015). Peningkatan keaktifan dan hasil belajar siswa dalam pembelajaran PKn melalui metode sosiodrama di kelas 5 SD Tlompakan 01-Tuntang. Scholaria: Jurnal Pendidikan Dan Kebudayaan, 5(3), 120-135.

Huda, Miftahul.2014. Model-Model Pengajaran dan Pembelajaran. Yogyakarta: Pustaka Pelajar. 
Hussaini, I., dkk. (2016). Improving Nigerian and Malaysian Primary School Students Vocabulary Skills Using Flash Cards. International Journal of Research and Review, 3(7): 20-25.

Peraturan Menteri Pendidikan dan Kebudayaan Widyastuti, Nuni. (2015). Efektifitas Model Republik Indonesia Nomor 21 Tahun Pembelajaran Time Token Arends 2016 tentang Standar Isi Pendidikan Terhadap Keterampilan Berbicara Dasar dan Menengah. Bahasa Indonesia Siswa Kelas V SD

Priyatno. 2017. Panduan Praktis Olah Data Bakalan Sewon Bantul Tahun Ajaran Menggunakan SPSS. Yogyakarta: Andi. 2015/2016. PGSD Universitas PGRI

Safitri, R. W., Primiani, C. N., \& Hartini, H. Yogyakarta: 1-5. (2018). Pengembangan media flashcard tematik berbasis permainan tradisional untuk kelas IV sub tema lingkungan tempat tinggalku. Premiere Educandum: Jurnal Pendidikan Dasar dan Pembelajaran, 8(1), 1-14.

Setiawati, N. L. M., Dantes, N. \& Candiasa, I. M. (2015). Pengaruh Penggunaan Media
Gambar Flash Card Terhadap Minat Dan Hasil Belajar IPA Peserta Didik Kelas VI SDLBB Negeri Tabanan. E-Journal Program Pascasarjana Universitas Pendidikan Ganesha, 5(1): 1-10.

Shoimin. Aris. 2014. 68 Model Pembelajaran Inovatid dalam Kurikulum 2013. Yogyakarta: Ar-Ruzz Media.

Slameto. 2013. Belajar dan Faktor-Faktor yang Mempengaruhinya. Jakarta: Rineka Cipta.

Susanto, Ahmad. 2016. Teori Belajar dan Pembelajaran di sekolah Dasar. Jakarta: Kencana Prenada Media Group.

Widiatmaka, Pipit. (2016). Kendala Pendidikan Kewarganegaraan Dalam Membangun Karakter Peserta Didik Di Dalam Proses Pembelajaran. Jurnal Civics, 13(2): 188198.

Widihastrini, F., Widodo, S. T., \& Nasikhah, A. N. (2016). Pengembangan Game Education Pembelajaran PKn Materi Menghargai Keputusan Bersama Kelas V SD. Jurnal Kreatif:Jurnal Kependidikan Dasar, 7(1):81-91. 